GENERAL ARTICLE

\title{
Science, science-based technology and human values
}

\author{
S.N. Arseculeratne ${ }^{*}$ \\ Department of Microbiology, Faculty of Medicine, University of Peradeniya, Peradeniya.
}

Submitted: 10 January 2009 ; Accepted: 16 January 2009

\begin{abstract}
This essay addresses the central theme that moral philosophy, now termed ethics, was divorced from natural philosophy, now termed science, as long as three hundred years ago, when modern science began its spectacular growth. This dichotomy has given rise to accusations that science functions without ethical concerns. The disastrous or sometimes ill-advised uses of technology derived from science, that are sometimes tragic, are the result of ignorance, scientific illiteracy or deliberate insensitivity and lack of ethical sense of persons involved in governance and application of science-based technologies, and not necessarily and primarily the fault of the scientist him/her-self. The divide between the sciences and the arts and humanities, considered in the idea of The Two-Cultures, together with scientific illiteracy in the main, contributes to this situation. The reconciliation of these two components of the divide, through a sound education, is argued to be of crucial importance and urgency.
\end{abstract}

Keywords: Education, human values, science, sciencebased technology, scientific illiteracy, The Two-Cultures

\section{INTRODUCTION}

Science can justifiably claim to be man's greatest intellectual enterprise, while there are its spectacular contributions, for example, to nuclear power and to medicine - the eradication of small pox, the use of penicillin, the genetic revolution; these gave science the aura of invincibility, of being the solution to all our problems. Yet some of these achievements also caused enormous ethical problems that are the subject of this essay. Statements have been made that imply that there is a gulf between science and ethical values, and that efforts are needed to bridge this gulf; for example, Mahatma Gandhi is claimed to have considered 8 'blunders' that create a world of violence ${ }^{1}$; the $5^{\text {th }}$ was 'science without humanity'. Feigl ${ }^{2}$ enumerated what he considered to be popular misconceptions of science; that, to paraphrase some of the criticisms he quoted are-

-the reality beyond appearances is beyond the reach of science

-science is responsible for the evils and maladjustments of our civilization

-the ethical neutrality of science could generate an indifference to the problems of humanity.

-while the scientific method being mechanistic or materialistic and reductionist, is successful in the explanation, prediction and control of physical phenomena, it is less successful in regard to the facts of organic life and even less so in the mental and social realm

-its methods can never replace intuitive insight or empathic understanding of what the psychologist, psychiatrist, anthropologist or historian deals with

-science cannot determine values.

Koestler ${ }^{3}$ wrote: "Our hypnotic enslavement to the numerical aspects of reality has dulled our perception of non-quantitative moral values....".

Even more telling is Albert Einstein's comment: "Science without religion is lame; religion without science is blind".

Discussions on the gulf between modern science and technology and human values have been held in the West. There have been increasing concerns about ethics in biomedicine, that have considered cultural relativism in medical ethics, and there is the need for education 
of our doctors in Asian ethics. In medicine there are also the materialistic goals of medical technology, and questionable acts in the practice of commercialized medicine. But despite our exposure to both modern science and Asian religious values, this debate has yet to be initiated here.

My view, in synopsis, is that the problem lies in the applications of science which, is ethically neutral in its theoretical framework, and any relevance of ethical considerations can only be in the applications of science such as in experimentation on animals and even human subjects, or the ethical connotations of procedures in assisted human reproduction or in the adverse environmental effects of technology, and the use of science based technologies as in germ warfare.

\section{What is science?}

Formal sciences include mathematics as an example of an abstract science that develops from 'thought experiments'; the empirical sciences are biology, chemistry and physics; the latter two are sometimes called the hard sciences. These divisions constitute natural philosophy, or natural sciences; the social sciences are sometimes called the soft-sciences. Science uses empiricism and theoretical reasoning, while religion is based on faith, and practical reasoning. In other words, the differences between the moral philosopher and the scientist are based on sentiment versus reason, respectively. Emotivity is the base of ethics. Positivity, and hence its practitioners, the positivists or logical positivists, was the hall-mark of scientists with their "objective methods of empirical science" ${ }^{4}$.

Science has three aspects that concern us. Firstly it is a body of organised knowledge and secondly, it has been acquired through well- (or sometimes ill-) defined methodologies and approaches, noting, contrary to popular belief, that there is no such thing as The scientific method. The findings of science, its factual content, are necessarily approximations to the truth and theories based on such data are constantly changing or evolving. The identification of what is science and what is not, is through more-or-less well-defined methodologies and criteria; however the goal-posts of this game might need shifting with developments in the philosophy and methods of science.

Science, for Vance Hall is 5 "essentially the gathering of neutral, value-free things called 'facts' from the rocksolid world of empiricism"; and according to the longheld, classical view, the process of scientific discovery begins with the dispassionate observation of facts through empiricism, induction towards generalised theories or hypotheses from these facts objectively, attempting to prove these hypotheses, and if they are successfully validated, then scientific knowledge and theories are established. "....the legend that science is a purely rational pursuit, that the scientist is a more 'levelheaded' and 'dispassionate' type than others.......or that he is able to provide for himself and his contemporaries, a rational substitute for ethical insights derived from other sources", so wrote Koestler ${ }^{3}$, is also a common belief that is often the basis of his confrontation with its critics. But this view of the linear process of the growth of science is probably not what really happens and is now quite obsolete.

\section{What are Values?}

As much as there are several types of intelligence (mathematical, emotional, aesthetic and so on), values may exist in various forms, those that are primarily relevant to the individual such as aesthetic values, or political values derived from affiliation to political theories or parties. The origins of human values are sometimes nebulous and ill-defined but they are determined from our childhood and may be even by our genes.

There are, then, those values that arise in his interactions with society which as Hemple quotes them are "egoistic, altruistic, hedonistic and utilitarian"; Dr Mahathir Mohammad, former Prime Minister of Malaysia in his crusade against unbridled westernisation, spoke of 'Asian Values'. During the early years of World War II, Victor Gollancz wrote a book titled "Our Threatened Values" referring to the threat to freedom and democracy that Nazism posed. These values and others such as 'goodness', 'justice' or 'fundamental human rights' do not seem to be immediately in the province of science. But there is one sense in which values come, or should come, into the application of science; this arises from the social function of science, on which Julian Huxley commented $^{6}$ : ".......science is not the disembodied sort of activity that some people would make out, engaged on the abstract task of pursuing universal truth, but a social function intimately linked up with human history and human destiny. And the sooner scientists as a body realize this and organize their activities on that basis, the better for both science and for society"; that statement underscores what I will repeat later that an urgent priority is that our education must be reoriented to provide the links between the sciences and the humanities that could give us those perspectives of human history and human destiny. It is for this reason that scientists were in the forefront of the Pugwash Movement. But as I argue later, 
it is in the later applications of scientific discovery that ethical problems arise.

In terms of the view that science is ethically neutral it was written ISI Press Digest 1984, 9(2): 69: “...the alleged split between the cultures of science-technology and humanism 'generates the illusion that science is morally neutral.... Though it is very understandable that a scientist when confronted with the stupidity of naked power and violence would withdraw into the peace of his research and truth, still such isolation is a peculiar form of conceit and arrogance. Scientists are responsible for all they do and for what they fail to do...."

To understand the background to these comments, it is useful to consider briefly the history of modern science.

\section{The history of natural philosophy and the origins of the divide}

It seems to me that the negative views on science as being without an ethical basis or that it is an illusion that science is morally neutral, arise from a misunderstanding of the nature and the history of science. Science grew out of a need to understand nature or as Aristotle said "All men by nature desire to know". During the last four hundred years, during which modern science grew rapidly in Europe bringing about what is usually called the scientific revolution, there was first the aim of understanding natural phenomena, then of mastering nature, and next controlling them and to use them for our purposes. The application of the results of scientific exploration for the use by man, that is technology, was an early enterprise; "The ability of natural philosophical knowledge to yield practical outcomes and to produce the means for technological control of nature was taken as reliable tests of its truths" ${ }^{7}$ and from that enterprise arose the ethical problems that we face.

Science, in its early period, was called a system of natural philosophy (from whence the title of the contemporary research degree of Doctor of Philosophy is derived). Science was concerned with the phenomena and events of nature and its practitioners were then known as natural philosophers; "New philosophers" was the term by which contemporary scientists were known during Francis Bacon's time in the $17^{\text {th }}$ century and the "term 'scientist' was invented only in the nineteenth century" 7 .

Incidentally, I was surprised that none of 10 young academics in our faculty with a $\mathrm{PhD}$, could tell me why their degree is called a Doctorate in Philosophy; that says much for the incomplete education in science that they received and of their scientific illiteracy.

When it appeared to be the case, as Feigl wrote ${ }^{2}$ that: "... it is true that science cannot dictate value standards", it occurred to me that this began centuries ago when the moral philosophers (now called the ethicists) and the natural philosophers (now called the scientists) began their work on divergent lines and through different approaches, and that this consideration is a useful starting point for this discussion.

Take some comments on fundamental differences between a scientist and a moral philosopher in their ways of thinking:- ${ }^{8}$

(1) Sophists of the $6^{\text {th }}$ c BC Greece - Plato, Aristotle, recognized Nomos, convention (morality), and Phusis, nature, that is observable and empirical. The division between the approaches of natural philosophy and moral philosophy had its origins even as early as that.

(2) Science was not concerned with 'moral philosophy'; Moral philosophy inquires into rational foundations of moral judgements. Indeed one of the prime societies of scientists, the French Académie Royale des Sciences, "announced its intention that in the meetings, there will never be a discussion of the mysteries of religion or the affairs of state'. Such subjects, it was thought, could only divide people, and by the 1660s there was already some bitter experience with philosophical societies that split apart along grand metaphysical fault lines" ?.

C. P. Snow" reminded us that ".... the Royal Society, early this century, deliberately excluded from its scope the social sciences and other fields of learning which, in other countries, would be regarded as part of 'science' in its universal sense"; The Royal Society of London is the oldest and most prestigious scientific society in the world.

(3) Wilhelm Dilthey argued that the method of the human sciences necessarily differs from that of the Naturwissenschaften. Knowledge in the latter concerns reality external to the mind and its products; knowledge can therefore be formulated as statements of causal relations. By contrast, the Geisteswissenschaften pursue objective knowledge through 'understanding' [verstehen], requiring the interpretation of meanings and their objectification in individual experience and socio-cultural products (such as art, mythology, or historical institutions)"; ${ }^{10}$ it should be added that Smith's "individual experience" is of a private nature, such as in meditation or religious experience that contrasts with a science that has been described as 'public' and hence open to public verification or falsification. 
(4) There is a contrast of reason, which is what science has, while sentiment or passion (David Hume) is central in morality; the ultimate moral decisions rest not on human reason but on sentiment.

(5) Moral philosophy is ethics that was concerned with values rather than facts which natural philosophy dealt with.

(6) Science as a discourse conforms to the methods of reasoning - induction and deduction as in the empirical sciences - that are rational. Reasoning in ethics as in other spheres of value-discourse cannot be said to conform to such a method.

(7) Science contrasts with ethics as one discipline in the humanities, with its recourse to reason, logic, induction and deduction, and the empiricism that uses sensederived data.

(8) Moral problems are not assessable by the senses that are the routes of scientific empiricism.

Sheldrake, in Morphic Resonance. The Presence of the Past. The Habits of Nature ${ }^{11}$ stated: "Pythagorean mystical experience was not in conflict with reason, but rather in harmony with it; for reason itself was considered above all the ability to experience proportions and ratios. Indeed this insight helped to shape the Greek understanding of the rational - that which is concerned with ratio. Reason came to be regarded as the highest aspect of the soul, that which is not only closest to the divine, but actually participates in the divine nature........ Although the Pythagoreans are often regarded as prototypic natural scientists, they were in fact steeped in a mystical and prescientific experience of the world." That comment is also relevant to the Two-Cultures that I will refer to later.

To summarize some views of Professor P. D. Premasiri (2005, personal communication),

(9) There is a difference in the way reason is used in establishing a scientific judgement and the way reason is used in establishing a moral judgement

(10) The ultimate standards of morality are non-rational in the sense of the use of 'induction' and 'deduction' that scientists use.

(11) Rationality, in the sense in which it is used in the sciences, in morals applies only to the factual bases of a moral judgement and not to the moral judgement itself

(12) Some early $20^{\text {th }}$ century philosophers considered ethical statements to be meaningless.

(13) The logical positivists (or empiricists such as Morris Schlick, Karl Popper, Ludwig Wittgenstein, A. J. Ayer) argued that statements in religion, ethics, and metaphysics are cognitively meaningless and have no connection with factual knowledge. This view accentuated the division between the natural philosophers and sciences and the moral philosophers.

(14) There is a large body of literature in which reason is contrasted with faith, (and by implication that there exists a gulf between science based on reason and religion based on faith).

(15) In the 20 $0^{\text {th }}$ century, moral philosophy moved away from moral truths towards logical and conceptual issues.

It is illustrative of the zeal with which the natural philosophers of the early decades of the growth of modern science, notably the (logical) positivists, regarded the potential of the scientific enterprise, who "dismissed all such questions (the beginning of everything, the meaning of life) as non-questions or pseudo-questions" ${ }^{12}$, and ultimately "Science and medicine were challenging religion as meanings of existence.....Seeking to understand and change society, Enlightenment thinkers looked to science for their model. It was seen as an incomparable engine of analysis: objective, critical and progressive" 13 .

Koestler's phrase 3 "parting of the ways" between the scientist and his science from the ethicist or moralist and his ethics, implies that while both were initially engaged in ethical considerations, the later abandonment of moral philosophy by the natural philosophers took place. It is worth quoting him on the consequences of this parting of the ways of the moral philosophers and the natural philosopher-scientists, if only because his vivid comments remind us of the very problem we are discussing - science and human values: "Freed from mystical ballast, science could sail ahead at breathtaking speed to its conquest of new lands beyond every dream. Within two centuries it transformed the mental outlook of Homo sapiens and transformed the face of his planet. But the price paid was proportionate: it carried the species to the brink of physical self-destruction, and into an equally unprecedented spiritual impasse". To use a Biblical metaphor, the 'parting of the ways' was not an act of commission as the eating of the forbidden apple by Adam was, and then his parting from the Garden of Eden; if the ethicists want to blame the scientist, it should be for an act of omission, the original sin, on the latter's part.

I'd rather think that there was necessarily a difference in viewpoints of these two groups ab initio as the fifteen points stated above indicate, the natural philosopher studying nature for its own sake. Thus Mendel was concerned with the quantitative aspects of what we now 
know as genetically-based inheritance of characteristics; he did not foresee the molecular biology of the gene and DNA that gave rise to the ethically complicated issues in human reproduction that we grapple with today; nor were Democritus $\left(4^{\text {th }} \mathrm{c} \mathrm{BC}\right)$ and John Dalton aware of the possibilities of exploiting the forces of nuclear fission, when they proposed the theory of atoms, while the reductionist physics of fundamental particles finally made possible the use of nuclear power. I doubt if ethical connotations are identifiable in Mendel's or Dalton's seminal writings.

The natural philosophers were thus not concerned with moral philosophy and the division of labour, as it were, occurred early in the history of science, that perhaps also initiated the separation of the Two-Cultures.

"From the $14^{\text {th }}$ century, Europe's cultural and intellectual life was undergoing mighty rebirth.." ${ }^{13}$.

There were overlapping movements with the scientific revolution; there was the enlightenment, and the growth of humanism. But it is odd that despite the ideas of humanism there was this so-called separation which prompted Edward O. Wilson to comment ${ }^{14}$ : "Since the decline of the enlightenment in the $18^{\text {th }}$ century, Western scholars have steadfastly partitioned knowledge into three great branches: the natural sciences, the social sciences and the humanities. They have also assumed that the line between the natural sciences on one side ('science') and the humanities and more humanistic social sciences on the other side is a permanent epistemological discontinuity". Snow ${ }^{9}$ as pointed out above, also reminded us that "...the Royal society, early this century, deliberately excluded from its scope the social sciences and other fields of learning which, in other countries, would be regarded as part of science in its universal sense".

A word on the relation between science and technology. Early technological inventions, such as steam engines and clocks, arose from human ingenuity, and the nomothetic bases of their functioning came much later; I remember reading somewhere an account of an ancient intricate Greek clock that was found on the bed of the Ionian sea. It is said that despite Edison's many inventions based on electricity, he did not know of Ohm's Law. While these inventions gave rise to the theoretical bases that comprise nomothetic science, technology in turn was then further developed as applied science, for example the increased efficiency of steam engines through the science of thermodynamics, and electricity to electronics. Shapin ${ }^{7}$ however thought it "unlikely that the 'high theory' of the Scientific Revolution had any substantial directeffect on economically useful technology in either the seventeenth century or the eighteenth. Utilitarian motives among many modern philosophers do not automatically equate with substantial economic consequences...". Shapin ${ }^{7}$ however points out that R.K. Merton, the proponent of the theory about the social and cultural relationships of science, notably economic and military aspects, "claimed to have showed a clustering of scientific work of the early Royal Society in areas of potential economic or military application......”.

This brief history suggests two contexts of science;

(i) Firstly science as an intellectual exercise that leads to the exploration of nature for its own sake and the establishment of a scientific culture. In this first context, there is the consideration of what constitutes scientific activity and what is scientific. This spills over into the current debate on the relation between science and paranormal phenomena and what is non-science.

(ii) The second context is the growth of sciencebased technology that we use. It is in its second context or role that the confrontation with human values and ethics arises, mainly from man-made decisions, outside the purview of science - such as the use of nuclear physics to produce and use the atomic bomb; on the other hand nuclear technology has the beneficial promise of a vast source of energy. There are grey areas such as the use of chemical knowledge to make agrochemicals, the misuse of which can cause degradation of the environment. The point that I wish to emphasize is that it is irrational therefore to lay the blame for the root causes of wars for example, primarily on science as science. The exploitation of science-based technology needs to be guided by the ideas of humanism and ethics if we are to avoid these adverse applications. This is why I titled this discussion - Science, science-based technology and human values rather than simply Science and human values.

\section{Intrinsic values of science}

If it is concluded that science is without a basis of moral philosophy or societal ethical values, it must however be realized that science has its own intrinsic values, that are 'internal' to its methods and philosophy.

Firstly, the role of values in the conditioning of the scientist in his creative thinking. The early history of modern science has an example of religious 'values' that guided its practitioners. The early scientists of the Renaissance, Kepler and Newton, so Koestler ${ }^{3}$ wrote, "based their search into nature on the mystic conviction....that the world was a completely rational, 
ordered harmonic creation..." and quoting a modern historian of science - Butterfield ${ }^{15}$, the "...aspiration to demonstrate that the universe ran like a piece of clock-work...was itself initially a religious aspiration" indicating a basis of religious values. But then followed what Koestler $^{3}$ called the 'estrangement' when "The mechanical universe could accommodate no transcendental factor" and "Cut off from what was once called the philosophy of nature and now exact science, theology continued its own specialized, doctrinal line.... To the inquiring intellect, the established churches became venerable anachronisms" bringing about what Whitehead ${ }^{16}$ referred to as "...a gradual decay of religious influence in European civilization...For over two centuries religion has been on the defensive, and on a weak defensive". The content of science notably the idea of biological evolution was in conflict with the idea of special creation of man and was a continuation of the rift between science and the orthodox Church. At this contextual level, Buddhism however advises that imponderables such as the origin of the universe are beyond human understanding and that it is advisable to spend one's efforts dealing rather with the 'now', of his personal predicament.

Before I read McMullin's essay ${ }^{17}$ Values in Science, I had annotated two significant cartoons by Sidney Harris; the first was on page 31 of There Goes Archimedes, ${ }^{18}$ the annotation of which ${ }^{19}$ was: "Investigators also sometimes choose between competing hypotheses as a result of nonscientific beliefs. Robert Fludd, one of the early supporters of William Harvey's theory of blood circulation, favoured Harvey's hypothesis because it supported Fludd's belief in the basic parallel between the cosmos (circular motion of the planets) and man (circular motion of blood)". The second annotation was on page 62 of At Home with the Einsteins ${ }^{20}$ in a cartoon titled "If Newton was a Botanist" and its annotation from Richard Jones ${ }^{21}$ read: "This leads him (Paul Feyerabend) to the controversial conclusion that competing theories are equally reasonable alternatives with one being eliminated in favour of another only as a result of subjective choice. 'What remains are aesthetic judgements of taste, metaphysical prejudices, religious desires, in short, what remains are our subjective wishes ". The point that McMullin ${ }^{17}$ made (as much as these annotations did) is that value-judgements from prior conditioning do enter into a scientists interpretation of what he observes and in the formulation of his theories.

Another example of an intrinsic value of science, is the use of Ockham's (William of Ockham's) razor in maintaining an economy and simplicity of hypotheses and theories. In the content of science are the predictive value of scientific theories and their explanatory cohesiveness.

Other values in the practice of science spring from or are related to general ethical values, or morality that underlies a stable human society; here it is in the community of scientists, their values of integrity in scientific writing, recognition and acknowledgement of prior work, acknowledgement of authorship, and the avoidance of fraud in recording and reporting of results. ".... we must continue to insist that honesty in experimentation, openness to rival views, and criticism of established views are values honoured in science, and to an extent enshrined in its institutions ${ }^{22}$. To Bronowski ${ }^{23}$, 'originality', 'dissent', 'freedom' and 'tolerance' are key values of the scientist. Bronowski includes 'independence in observation' and 'hence in thought'; this point is debatable and I will discuss it later with reference to McMullin's views. Given the nature of science as a 'public' enterprise that involves the interaction of scientists with each other and above all the potential application of those results for our use, the need for such values becomes obvious. Some of these are implied in the flavour of the Enlightenment that was an overlapping movement with the scientific revolution and which produced the first modern secularized theories of psychology and ethics and which became critical in reforming and revolutionizing higher forms of social organiazation based on natural rights (Encyclopaedia Britannica). An essential characteristic of the enlightenment in the $17^{\text {th }}$ and $18^{\text {th }}$ centuries, was the emancipation of human thought from superstition and ignorance through the application of reason.

The growth of Humanism was of prime importance to human values and was the central theme of the Renaissance; Humanism dealt with "value systems that emphasize personal worth of each individual" (Encyclopaedia Britannica). The Humanities comprised the liberal arts, values and culture. We will talk about the Humanities again, later.

Although science is considered to be ethically neutral, while the word 'values' in the sense of this essay refers to ethical values in human society, there is another sense in which the question of 'value-judgements' enters the scientific enterprise.

\section{What can we do about the lack of moral values in science?}

The question then is, can science guide us in making moral choices on situations that we face? A reading of the literature seems to indicate a consensus that science per se is ethically neutral. On this view Russell 
wrote 24 “Questions as to 'values' - that is to say, as to what is good or bad on its own account, independently of its effects - lie outside the domain of science, as the defenders of religion emphatically assert"; "The sort of questions that science can answer are those that can be answered or "validated by empirical experience" 12 which the ultimate questions don't lend themselves to. A useful guideline was stated by Hempel ${ }^{4}$; "It was Max Weber, I believe, who expressed essentially the same idea by remarking that science is like a map; it can tell us how to get to a given place, but it cannot tell us where to go". Take three examples of situations that demand moral choices and to which Weber's comment is relevant.

First, the decision to use the atomic bomb on Japan to end World War II. Science and then its derivative technology had provided the material and the methods, and data on the consequences of its use, but the choice of its use, to drop or not drop the bomb, was essentially a military decision that should have had a large overlay of moral or ethical choice of the politicians, noting also that scientists including Robert Oppenheimer were on the Manhattan Project that developed the first atomic bomb. Prominent scientists including Einstein had of course earlier advised the US President of the impending danger of the Nazi development of atomic power for military purposes but after the event of the bombing of Japan and the unfolding of the horror of the devastation, united to condemn its use, on moral grounds. Medawar ${ }^{12}$ quoted a former editor of the London Sunday Express who wrote "Science gave us the Great War", adding that it was "blaming the weapon for the crime" and perhaps blaming science for "nationalism, bungling politicians and ambitious generals...." on whom the blame, at least the greater part of it, should squarely be laid. In this instance, the content of science gave us the knowledge of the methods for the exploitation of nuclear power, as well as the biological consequences of a fall-out, the content that should guide, as Max Weber said, moral decisions on the use of nuclear power.

Take another example, the dilemma of whether to continue or discontinue life support for a patient who is in the terminal stages of an incurable illness. The medical facts provided by science are known; but the moral choice rests on the patient's relatives, and may be culturally determined. Another example is the use of a heart from a recently-dead person, for transplantation; the story that I was told was that "....the donor was a young black man who had met with a road accident the previous day. It was....in the mortuary of the Grote Schuur. Two black women, the mother and sister of the donor were confronting a white-coated white man. The women had just been told that they could remove the body for the funeral, but they were disturbed for they were wondering, what was the use of a body without the heart?". Apparently heart transplantation was making hardly any progress in Japan, as donors were very scarce, for families were of the opinion that bodies without hearts were pretty useless: “....up until 1997, Japan resisted the idea that brain death represents the end of a person's life. The usual explanation for this unusual standpoint - which effectively ruled out heart transplantation in Japan for almost three decades - has been that many Japanese believe that a person's body may be inhabited by a soul even after death, and do not like the thought of a family member's dead body being 'invaded' for the removal of organs or tissues" ${ }^{25}$. I would assume that the situation would be different in other countries and this emphasizes the point that the science and technology of heart transplantation has little or nothing to do with the moral choices involving organ donation and acceptance. In other words, the scientific basis of transplantation was similar in both Africa-Japan and in the West although ethical considerations were different in these two culturally different contexts, underlining the reality of cultural relativism of medical ethics ${ }^{26}$.

There are other areas such as the injudicious use chemical knowledge for the manufacture of agrochemicals, the misuse of which by commercial vested interests, or as Medawar claimed of nineteenth century "laissez-faire capitalism and the philosophy of commercial advantage" as having caused the despoilation and pollution of the nineteenth-century countryside, and ignorant and greedy lay-people can cause degradation of the environment causing the "Silent Spring" of Rachel Carson.

".... a moment's reflection shows that the problems that need to be dealt with are not straightforward technological questions but intricate complexes of technological and moral issues" 4 . It becomes irrational therefore to lay the blame for these adverse situations primarily on science as science, or on scientists as scientists. On the other hand it is possible that the isolation of science is heightened by the arrogance of some scientists in their ignorance of the limitations of science, who regard it as the only valid basis of our actions. As Medawar said ${ }^{12}$ : "The existence of a limit to science is, however, made clear by its inability to answer child-like elementary questions such as "How did everything begin?, What are we all here for?", and "What is the point of living?" and he proceeds to "explain why science cannot answer these ultimate questions and why no conceivable advance of science could empower it to do so". 
The situation that we are faced with is then, as stated by Hempel ${ }^{4}$ "... if science cannot provide us with categorical judgements of value, what then can serve as a source of unconditional valuations? This question may either be understood in a pragmatic sense, as concerned with the sources from which human beings do in fact obtain their basic values. ..... What science can provide is a test of an assertion of a relationship between a cause and an effect, such as between a drug and its alleged therapeutic effect, but cannot provide a test of a relationship that involves terms of moral discourse - such as good, better, ought to". Hempel 4 used the example of morphine that will ease the pain from an incurable illness; that is knowledge acquired through the pharmacology of morphine, but pharmacology does not help us to decide whether it is 'good' to "prolong the patient's life, if also his suffering" . Cultural relativism is involved in the question of euthanasia; it involves the notion that "killing is evil"; all killing is abhorent to a Buddhist while ritual killing is acceptable to votaries of some other religions.

Again, "...categorical judgements of value, then, are not amenable to scientific test " ${ }^{4}$. Ultimate questions on what is good, and what is evil that are the substance of meta-ethics, are certainly outside the scope of science. The reality of cultural relativism in ideas on medical ethics ${ }^{26,27}$ makes me stress the point repeatedly that we, both medical practitioners and students, urgently need a proper education that sensitizes us to ideas and arguments on both sides of this divide.

If indeed science cannot answer some ultimate questions about life, then Medawar ${ }^{12}$ suggests that it is to "metaphysics, imaginative literature or religion that we must turn for answers to questions having to do with first and last things".

I have argued elsewhere that what appears to be on one side or the other of this divide are really so largely because of our methodological approach to their study and not to an intrinsic difference in their content. This view implies that an eclectic education is urgently needed to minimize this polarization. What needs to be done is the promotion of a broad-based education that bridges the gulf between the sciences and the humanities that exists in our country's education. Some of us are aware of the sort of eclectic education that is found in the US and to quote Feigl $^{2}$ again, he refers to progressivism or reconstructionism in American education that synthesizes "the scientific attitude with an active interest in the whole scale of human values".

Conversely are situations in which ethical considerations can guide the scientist, as Professor
Premasiri pointed out, in experimentation on animals. There are now such guide-lines from WHO as much as there are those that deal with experimentation on humans, such as the Nuremberg Code that was prompted and formulated after the tragic Nazi experiments on humans during World War II.

\section{The Two-Cultures}

It seems to me that some of these statements on science and ethical values bear heavily on the Two-Culture debate - on the gulf between the sciences and the humanities that deal with the liberal arts, values and culture. You'd recall my recollection of Wilson's comment ${ }^{14}$ : "Since the decline of the enlightenment in the $18^{\text {th }}$ century, Western scholars have steadfastly partitioned knowledge into three great branches: the natural sciences, the social sciences and the humanities. They have also assumed that the line between the natural sciences on one side ('science') and the humanities and more humanistic social sciences on the other side is a permanent epistemological discontinuity". Koestler" noted that in the "index to the six-hundred odd pages of Arnold Toynbee's A Study of History, (abridged version), the names of Copernicus, Galileo, Descartes and Newton do not occur".

\section{Is there a divide between the Two Cultures?}

As discussed earlier ${ }^{28}$, a large part of the seeming divide between these two areas of intellectual activity is artefactual arising from differences in investigative approaches and methodologies; similarly Wilson wrote: 14 "...the divide is not a fault line, and in fact is not a line at all', and the 'tools of thought' as Bateson ${ }^{29}$ expressively worded it, on each side of the divide, can be used to explore the content of either the sciences or the humanities. I can think of no better example than the work of Andrew Newberg et al. ${ }^{30}$ who demonstrated through sophisticated brain scans (belonging to hard-core science) that mental activities that hitherto lay squarely in the province of the humanities, such as the existence of a soul and belief in a god, have a physical-biological basis that is amenable to neuro-scientific exploration. As illustrations of these trends, Moss ${ }^{31}$ in an essay in the same publication of the New York Academy of Sciences that included Wilson's essay, wrote: "Neurobiology will inform and redefine psychology. Evolutionary theory, cognitive neuroscience, and information theory will have an impact on sociology, economics, history, literature and art".

\section{The core of the division that yet seems to exist}

Following my view of the Two-Cultures, that approaches and methodology can blurr the apparent divide, there yet 
seem to be areas that still do not fall within both spheres and the problem, posed by Johannes Muller, quoted by Stone $^{32}$ still remains; "Johannes Muller (1801-58), the great German physiologist, suggested a compromise widely accepted, i.e., that there are two sorts of living phenomena; one the result of physico-chemical causes and amenable to experimental inquiry, the other explainable only by the action of a vital principle and outside the domain of science"; "...the old explanations, with all their arbitrariness and patchiness, answered the question after 'the meaning of life' whereas the new explanations, with all their precision, made the question of meaning itself meaningless" 3 .

\section{What can education do to bridge the divide?}

While these new trends in science and education are proceeding apace towards a synthesis in the West, it is depressing to note, as Douglas King (a commentator on education in Sri Lanka) wrote (The Island, 15 June 2005, page 11); "Education: Let's get our priorities right": "Let us welcome ICT (Information and Communication Technology) but first let us get our priorities right" and I think, the elimination of our Two-Culture divide and the meaningless streaming in our education into the sciences on one side and the so-called arts subjects on the other, is certainly one of the priorities that our educational pundits have never considered; I have discussed this earlier, that our narrow educational perspectives are primarily responsible for this artificial division. Even in countries such as the US where education is far more eclectic, discussions have taken place on this unfortunate dichotomy. "We need especially to develop the ability to estimate rationally and to choose between alternate courses of action.... we need the humility to admit that we will not find any absolute answers or permanent solutions....we must find ways to judge these solutions as parts of a more comprehensive social system in which they must be compatible... No longer should we do something - whether in the civilian sphere or the military - just because we can....." and that we "will have to be broadly knowledgeable in order to deal with system problems in which the economic, ecological, esthetic, social and other human aspects may be as crucial as the technical issues, perhaps sometimes even more important" ${ }^{33}$.

The ablation of this artificial divide appears to be the only solution, as Feigl ${ }^{2}$ has cogently argued; "There is an important common element in mature thinking (as we find it in science) and mature social action (as we find it in democracy): progress arises out of the peaceful competition of ideas as they are put to the inter-subjective test. Cooperative planning on the basis of the best and fullest knowledge available is the only path left to an awakened humanity that has embarked on the adventure of science and civilization", while Bateson ${ }^{29}$ argued: "I felt that if they were going to be doctors (medical doctors) of the human soul, they should have at last a foot on each side of the ancient arguments. They should be familiar with the central ideas of both religion and science"

I firmly believe that it is only an eclectic, meaningful education that can enable us to achieve, in the words of J.D. Bernal, the Marxist scientist: "the most fundamental task for science" (which) "is to help interpret and understand society and its changes and thus to show how best the ethical motivations of mankind might be put to most effective and harmonious use" ${ }^{5}$. There is one matter that has been insufficiently stressed in this debate of science and values. That meaningful education I spoke of should not be directed only at the scientists, but more intensively on the very people on whom rests the onus for the application of science and technology, viz., the politicians, the administrators, commercial entrepreneurs and the lay people engaged in governance; the scientists have, for too long, been made the scape-goats of the illadvised actions of these categories of people.

\section{CONCLUSION}

Two points need emphasis; (1) If general moral-ethical guidelines that are the basis of the social contract in human society are offered to scientists, that guidance should be addressed, not to the scientist as a scientist, but to a scientist as a component of human society; of course, in the ethics of scientific experimentation on humans and animals, the scientist must be advised as a scientist; (2) How does this topic - science and human values - relate to our educational efforts? It does so through the second part of my argument, that is the integration of science with the humanities that are the source of the ethical principles and moral decision-making, in western as well as in Asian (or indigenous) cultural and religious literature, about which our scientists including doctors know very little.

\section{References}

1. Richardson J. (2005). Paradise Poisoned: Learning About Conflict, Terrorism, and Development From Sri Lanka's Civil Wars. p. 764. International Centre for Ethnic Studies, Kandy.

2. Feigl H. (1988). The scientific outlook: naturalism and humanism. In: Introductory Readings in the Philosophy of Science (Eds. E.D. Klemke, R. Hollinger \& A.D. Kline). p. 427. Prometheus Books, Buffalo, New York, USA.

3. Koestler A. (1959). The Sleepwalkers. Penguin Books, London, UK. 
4. Hempel Carl G. (1988). Science and human values. In: Introductory Readings in the Philosophy of Science (Eds. E.D. Klemke, R. Hollinger \& A.D. Kline). Prometheus Books, Buffalo, New York, USA.

5. Hall V.D. (1985). Ethics and Modern Science (unpublished lecture) p. 324. University of Malaya, Kuala Lumpur, Malaysia.

6. Huxley J. (1934). Scientific Research and Social Needs. Watts \& Co., London, UK.

7. Shapin S. (1998). The Scientific Revolution pp. 75-76. University of Chicago Press, Chicago, USA.

8. Premasiri P.D. (2005). Rationality of science and rationality of morals. In: Dialogue 1. Moral Directions in Science. Society for the Integration of Science and Human Values, Kandy.

9. Snow C.P. (1964). The Two Cultures, and a Second Look. Cambridge University Press, Cambridge, UK.

10. Smith R. (1983). Geisteswissenschaften and Naturwissenschaften. In: Dictionary of the History of Science (Eds. W.F. Bynum, EJ Browne \& Roy Porter). pp. 161-162. Macmillan Publishers Ltd, London, UK.

11. Sheldrake R. (1995). The Presence of the Past: Morphic Resonance \& the Habits of Nature $\mathrm{p} 20$. Park Street press, Vermont, USA.

12. Medawar P.B. (1984). The Limits of Science p. 60. Oxford University Press, Oxford, UK.

13. Porter R. (1997). The greatest benefit to mankind. In: A Medical History of Humanity from Antiquity to the Present p. 168. Fontana press, London, UK.

14. Wilson E.O. (2001). How to unify knowledge. Annals of the New York Academy of Sciences 935: 12-17.

15. Butterfield H. (1949). The Origins of Modern Science. Simon \& Schuster Inc., London, UK.

16. Whitehead A.N. (1953). Science and the Modern World p. 233. Penguin Books, Cambridge University Press, Cambridge, UK.

17. McMullin E. (1988). Values in science. In: Introductory Readings in the Philosophy of Science (Eds. E.D. Klemke, R. Hollinger \& A.D. Kline) pp. 349-371. Prometheus Books, Buffalo, New York, USA.
18. Harris S. \& Arseculeratne S.N. (1993). There Goes Archimedes p. 31. Unigraphics, Colombo.

19. Grinnell F. (1987). The Scientific Attitude. p. 40. Westview Press, Colorado, USA.

20. Harris S. \& Arseculeratne S.N. (1996). At Home with the Einsteins p. 62. Karunaratne Sons, Colombo.

21. Jones R. (1989). Teaching the History of Science (Eds. M. Shortland \& A. Warwick) p. 281. John Wiley \& Sons, Oxford UK.

22. O'Hear A. (1990). An Introduction to the Philosophy of Science p 216. Clarendon Press, Oxford, UK.

23. Bronowski J. (1961). Science and Human Values. Hutchinson and Co. (pvt) Ltd, London, UK.

24. Russell B. (1960). Religion and Science. p. 230. Oxford University Press, London, UK.

25. Takebe H. (2000). Bridging the gap. Odyssey 6(1): 8-9.

26. Pellagrino E.D., Mazarella P. \& Corsi P. (1992). Transcultural Dimensions in Medical Ethics p. 17. University Publishing Group Inc., Frederick, Maryland, USA.

27. Kumarasiri R., Arseculeratne S.N., Premasiri P.D. \& Simpson R. (2008). A comparison of responses to contemporary biomedical dilemmas among young people in Sri Lanka and England. Biomedical Law \& Ethics 2(2): 211-237.

28. Arseculeratne S.N. (2003). The two cultures - the sciences and the humanities: is there really a divide between the two?". Chief guest's lecture, Annual sessions, Sri Lanka College of Microbiologists, Colombo 07.

29. Bateson G. (2002). Mind and Nature: A Necessary Unity p. 23. Hampton Press, New Jersey, USA.

30. Newberg A., D'Aquili E. \& Rause V. (2001). Why God Won't Go Away: Brain Science and the Biology of Belief. Ballantine Books, New York, USA.

31. Moss H. (2001). Unity of knowledge, circa 2000. Annals of the New York Academy of Sciences 935: 1-11.

32. Stone K. (1966). Evidence in Science. p. 60. John Wright \& Sons, Bristol, USA.

33. Wiesner J. B. (1974). In defence of science and technology. Dialogue 7(1): 3-10. 